\title{
The Relationship Between Methylation Defects and Different Genetic Disorders: Two Case Reports
}

\author{
Emine AYDIN1, Ahmet Cevdet CEYLAN², M. Sinan BEKSAÇ \\ Ankara, Turkey
}

\begin{abstract}
5,10-methylenetetrahydrofolate reductase (MTHFR) is an important enzyme taking role in methioninehomocysteine and folate metabolisms. This pathway has been associated with gene specific DNA hypo and hypermethylation which results in gene switching on or off.

MTHFR C677T and A1298C gene polymorphisms are associated with folate metabolism disorders, that results in impaired DNA methylation and chromosomal abnormalities, gene deficiencies and structural anomalies. Here, we report two cases of compound heterozygote and homozygote MTHFR gene mutations associated with genetical disorders during their pregnancies.
\end{abstract}

Keywords: Chromosomal abnormality, Congenital malformation, DNA methylation, Methylenetetrahydrofolate reductase.

Gynecol Obstet Reprod Med 2016;22(2):110-112 DOI: 10.21613/GORM.2016.484

\section{Introduction}

5, 10-methylenetetrahydrofolate reductase (MTHFR) is a key enzyme, taking role in methionine-homocysteine and folate metabolisms (Figure 1)1,2. MTHFR catalyzes the conversion of 5,10 - methylenetetrahydrofolate to 5 - methyltetrahydrofolate, a co-substrate for re-methylation of homocysteine to methionine. This pathway has been associated with gene specific DNA hypo- and hyper-methylation, which results in gene switching on or off 1-3.

MTHFR gene polymorphisms cause folate metabolism disorders and it may result in an impaired DNA methylation. DNA methylation abnormalities cause chromosomal anomalies, gene deficiencies and structural anomalies 4,5.

In this paper, we are reporting two cases. The first case is with compound heterozygote for MTHFR C677T and A1298T gene mutations with complex obstetrical history. Her first pregnancy ended with a baby who had CHARGE syndrome and the neonate died at about two years of age. Her second pregnancy was terminated due to Turner Syndrome. Her third and fourth pregnancies were uneventful. Fetuses were healthy,

${ }^{1}$ Hacettepe University, Faculty of Medicine Department of Obstetrics and Gynecology and ${ }^{2}$ Department of Medical Genetics, Ankara

Address of Correspondence: Emine Aydin

Hacettepe University, Faculty of Medicine Department of Obstetrics and Gynecology, Division of Maternal Fetal Medicine, Sihhiye, Ankara, Turkey eminebaskurtaydin@gmail.com

Submitted for Publication: 02. 04.2015

Accepted for Publication: most likely due to the necessary precautions undertaken relaed to folate metabolism disorders.

The second case was with "A1298T homozygote mutation" at MTHFR gene, and she had a boy with Joubert Syndrome and her second pregnancy was terminated due to anencephaly. In her third pregnancy, she delivered a healthy baby boy under treatment protocol. Our treatment protocol during pregnancy consisted of low dose low molecular weight heparine, low dose salisilic acid, methionine restricted diet and supplementation of vitamins $\mathrm{B}_{1}, \mathrm{~B}_{2}, \mathrm{~B}_{3}, \mathrm{~B}_{6}, \mathrm{~B}_{12}$ and folic acid.

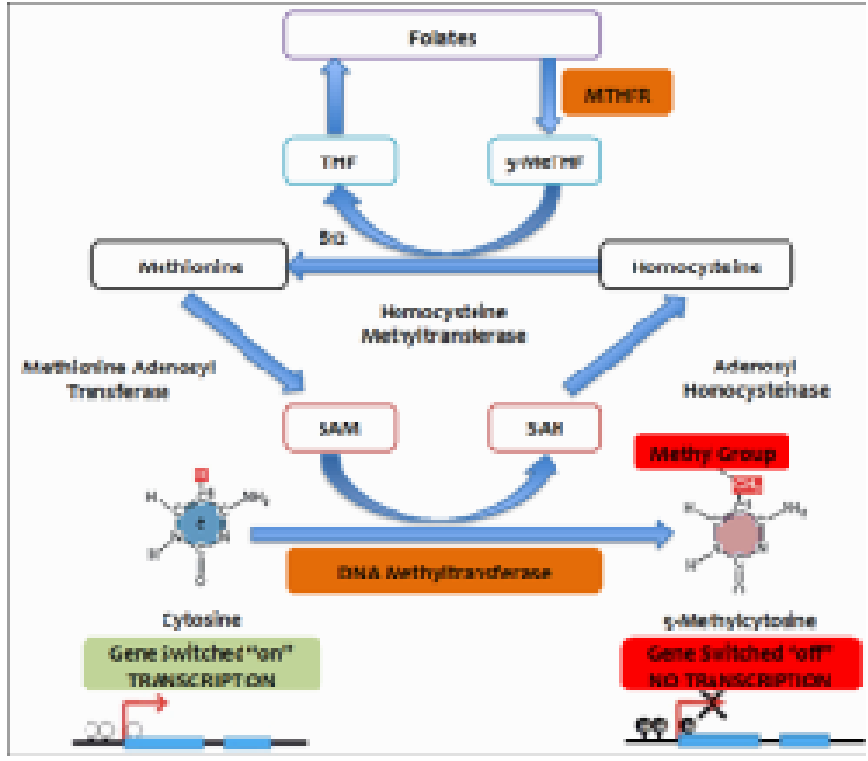

Figure 1: Methylenetetrahydrofolate reductase role in gene regulation and methionine- homocysteine metabolism 


\section{First Case}

A 38 year-old pregnant woman was admitted to our clinic with vaginal bleeding at $11^{\text {th }}$ gestational week. Her gravida was two and parity was one. Her first baby was born at $35^{\text {th }}$ gestational week via cesarean section. The boy had coloboma, bilateral nasal atresia, anal atresia, mental retardation and deafness. It was thought that baby was with Charge syndrome and he died after 19 months of age.

As mentioned above, she was admitted to our hospital during the course of her second pregnancy with vaginal bleeding. At obstetric sonography, there was no fetal cardiac activity. The pregnancy was terminated after a cytogenetic finding of fetal monosomy X (Turner Syndrome). There seemed to be no risk factor other than advanced maternal age. She was then tested for the C677T and C1298T variants in the MTHFR gene, and polymorphisms were found in a compound heterozygous state. Necessary precautions were taken preconceptionally and her third pregnancy started under our treatment protocol as mentioned above. Amniocentesis was performed at $18^{\text {th }}$ gestational week and the result was normal fetal karyotype. There was no structural abnormality at detailed ultrasonography. Delivery occurred at $37^{\text {th }}$ gestational week with cesarean section. This baby is still alive and healthy. Her fourth pregnancy was also under our medical control with necessary precautions. Amniocentesis was performed at 18th gestational week and determined as normal fetal karyotype. This baby was also considered to be genetically normal. The last two children are still alive and healthy without any medical problem.

\section{Second Case}

A 31 year-old woman was admitted to our department with bad obstetrical history. Her obstetric history was remarkable, her gravida was two and parity was two. The first baby was born at $37^{\text {th }}$ gestational week with cesarean section. He had delayed development at 2 years of age. Cranial imaging showed 'molar tooth sign' and he was diagnosed with Joubert Syndrome. At her second pregnancy, the fetus was anencephalic. Second pregnancy was terminated immediately at the $12^{\text {th }}$ gestational week.

The couple had no consanguineous and there seemed to be no other risk factor. She was then tested for MTHFR gene, and a A1298T homozygote mutation of MTHFR gene was found. She received folic acid, vitamin B supplementation and low dose salisalicylic acid together with methionine restricted diet preconceptionally. At the booking visit, serum levels of folic acid, vitamin B12 and homocysteine levels were all within normal limits. During her last (third) pregnancy she received our treatment protocol as mentioned above and followed carefully within the framework of our antenatal care program. A healthy baby without any genetical problem was delivered at the 37 th gestational week.

\section{Discussion}

It is known that lack of DNA methylation may cause congenital abnormalities. MTHFR catalyzes the synthesis of 5methyltetrahydrofolate. Methionine is synthesized from homocysteine in B12-dependent re-methylation pathway. Sadenosylmethionine (SAM) is the major cellular methyl donor for DNA, RNA, protein, and phospholipid methylation and methionin is SAM's precursor. The decrease in the enzyme activity associated with C677T MTHFR polymorphism necessitated the dietary supplement for folic acid to provide normal re-methylation of homocysteine to methionine.1 Consequently, low folate level at the MTHFR polymorphism results in an increase in homocysteine and a decrease in methionine levels. Chronic elevation of the homocysteine levels in the intracellular stage can cause a decrease in the ratio of SAM to S-adenosylhomocysteine (SAH) that is associated with inhibition of the DNA methyltransferase and DNA hypomethylation. 2

Meanwhile, methionine synthase deficiencies may also play an active role in the occurrence of mentioned genetical disorders (Because this enzyme plays an active role in the same enzyme pathway).

CHARGE syndrome's incidence is 5.8-6.7 per 100,000 live births. It is a highly variable, multiple congenital malformation syndrome, which can show clinical, overlap with other syndromes. Mutations of the chromodomain helicase DNAbinding protein gene $\mathrm{CHD} 7$ is reported to be a major cause of CHARGE syndrome.6 Turner syndrome is caused by loss of part or all of an X-chromosome. It is an important cause of short stature and primary amenorrhea in girls.7 In our case, both the patient and her husband had normal chromosomal karyotypes. Our case had C677T and A1298T polymorphisms in the MTHFR genes in a heterozygous state with a result of defective folate metabolism. To conclude, in cases of choromosomal abnormalities and congenital malformations, impaired DNA methylation should be kept in mind, and those patients should be tested for the genes involved in the folate metabolism. 4,5

Joubert syndrome is a disorder characterized by hypoplasia of the cerebellar vermis. 'Molar tooth sign,' is a characteristic neuroradiologic imaging. Neurologic symptoms accompany developmental delay and dysregulation of breathing pattern. 8 Anencephaly is a form of neural tube defect (NTD), which has been associated with several genes and environmental factors. The incidence of neural tube defects range from 1.0 to 10.0 per 1,000 births. Folic acid deficiency is critical in NTD pathogenesis.9 Our second case was an another example demonstrating the relationship of genetical disorders (e.g. congenital malformations) and MTHFR gene polymorphisms going together with impaired DNA methylation. 
In conclusion, impaired DNA met hylation due to MTHFR gene polymorphisms may be the result of fetal genetical disorders and obstetrical complications.

\section{References}

1. Bailey LB, Gregory J. Polymorphisms of methylenetetrahydrofolate reductase and other enzymes: metabolic significance, risks, and impact on folate requirement. J Nutr.1999;129:919-22.

2. Balaghi M, Wagner C. DNA methylation in folate deficiency use of $\mathrm{CpG}$ methylase. Biochem Biophys Res Commun. 1993;193:1184-90.

3. Hobbs CA, Sherman SL, Yi P, Hopkins SE, Torfs CP, Hine RJ, Pogribna M, Rozen R, James SJ. Polymorphisms in Genes Involved in Folate Metabolism as Maternal Risk Factors for Down syndrome. Am J Hum Genet. 2000;67: 623-30

4. Turgal M, Yazicioglu A, Ozyuncu O, Beksac MS. Impaired DNA methylation leading to heterotrisomy. J Obstet Gynecol. 2013;33:904-5

5. Beksac MS, Balci S, Guvendag Guven ES, Guven S,
Ozkutlu S. Complex conotruncal cardiac anomalies consecutively in three siblings from a consanguineous family possibly associated with maternal hyperhomocysteinemia, Arch Gynecol Obstet 2007;276:547-9

6. Martínez-Quintana E, Rodríguez-González F, GaraySánchez P, Tugores A. Novel Frameshift CHD7 Mutation Related to CHARGE Syndrome. Mol Syndromol 2014; 5:36-40.

7. Luca AC, Iordache C, Braha E. A case of Turner Syndrome associated with severe coarctation of the aorta. Rev Med Chir Soc Med Nat Iasi 2013;117:670-3.

8. Valente EM, Salpietro DC, Brancati F, Bertini E, Galluccio T, Tortorella G, et al. Description, nomenclature, and mapping of a novel cerebello-renal syndrome with the molar tooth malformation. Am J Hum Genet 2003;73:663-70.

9. Arth A, Tinker S, Moore C, Canfield M, Agopian A, Reefhuis J. Supplement use and other characteristics among pregnant women with a previous pregnancy affected by a neural tube defect United States, 1997-2009. MMWR Morb Mortal Wkly Rep 2015;64(1):6-9 